\title{
Driver Alert System for Hilly Roads at Hair Pin Bends
}

\author{
Bishwajeet Singh, Mohit Arvind, Divya Asija, Pallavi Choudekar, Ruchira
}

\begin{abstract}
In this paper we have proposed the time-based system for alerting the driver against other vehicle at hair pin bends to avoid accidents causing loss of human life. This system is designed to provide safe journey to the local residents and tourists by alerting them against blind spot curves and also reduced the possibility of accident at blind curves. This paper is focused on the designing of automated system with the advent of new technology and up gradation. The proposed automated system would remarkably reduce the human efforts by utilizing the PLCs. Automated system is taking place of human due to increased efficiency and quality output. Thus, the proposed system adopts the latest automated technology including PLC to develop driver alert system which has application on the hair pin bends of hilly roads.
\end{abstract}

\section{Index Terms: MCB, SMPS, PLC, Sensor, LED}

\section{INTRODUCTION}

Vehicles play an important role in our day to day life such as commuting from one place to another, transportation materials, foods etc. helping the humans by decreasing the time in travelling. As per the previous experiences and reports, we find that there are many accidents happening on hilly roads due to non visibility of other vehicle that is coming from other side, landslides and unfavorable weather conditions. But no precautions or measures have been taken to avoid them. This leads to the loss of human life.

Driver alert system is developed to avoid any possibility of accidents on hair pins using PLC based model. It will alert the driver timely about the vehicle coming from other side at blind spot curves/ hair pin bends so that both the driver can slow down their vehicles to avoid any kind of mishappening.

Nowadays we can see that industries are going towards automation as to increase the productivity and efficiency in limited time and reducing human efforts. So with each passing day we need good and technology equipped product with best quality and cheapest price. Quantity required is also in bulk amount. Thus manual production of the article is not capable enough to make these bulk orders with considerable superior quality and cheap cost.

Every industrial sector like manufacturing, process industries, chemical, food \& beverages, oil gas , transport, machine tools

Revised Manuscript Received on July 09, 2019.

Bishwajeet Singh, EEE, ASET, Amity University Uttar Pradesh, Noida, India.

Mohit Arvind, EEE, ASET, Amity University Uttar Pradesh, Noida, India. Divya Asija, EEE, ASET, Amity University Uttar Pradesh, Noida, India. Pallavi Choudekar, EEE, ASET, Amity University Noida, India.

Ruchira, EEE,ASET, Amity University Noida, India. everywhere industrial automation is used. It will increase productivity, safety, reliability.

\section{LITERATURE REVIEW}

Several research papers have been studied to develop the concept of driver alert system. Paper titled "Collision detection system for vehicles in hilly and dense fog" is about the collision of vehicle [1] in hill and dense fog by using the GPS technology which they called eye in the sky server which is basically captures the geographical location of the vehicle process the data and generates the alert alarm for the collision. In this paper [2] authors proposed the real time-based smart vehicle monitoring and alert by using GSM module to save the human life. Authors in this paper have explained the concept of blind spots in hilly roads which has reduced visibility resulting in many accidents occurring at the blind spots. It is real time-based smart vehicle monitoring and alert by using GSM module to save the human life.

An article is also available in literature which deals with "The road that honks" which is much similar to prototype [3]. It is the product of the joint venture by Hindustan Petroleum Lubricants and the Leo Burnett which is installing in Jammu \& Kashmir highway for save the human life. It has utilized the radar technology for calculating the vehicle speed and also honks when the vehicle is coming from the other side. It is thus the foremost important indicator to save the human life which very precious.

Several research papers are being published on automation work for e.g. automation of space management in vehicle parking using PLC and SCADA. In this paper [4] authors have identified the available space in parking area using industries electronic device PLC (Programmable Logic Controller) and SCADA (Supervisory Control and Data Acquisition) system. It involves different stages; from the main unit process is passed on to sub-unit to achieve the goal of automation. For both the entry and exit of the vehicle they designed a complete system to get notified of the entry \& exit of each and every vehicle getting in and out. The system is also communicating wirelessly with the driver of car and notifies them about the availability of empty parking lot. The whole system is controlled through a control room manned by personnel who monitors the activities within the parking lot.

In case of no space in parking area the entry gate will not open for the vehicle as there will be no space in parking lot. PLC and SCADA based automated are the best way to control the whole system by just sitting in control room and give commands to the sensors. It is the best way to do the automation work which requires less human efforts

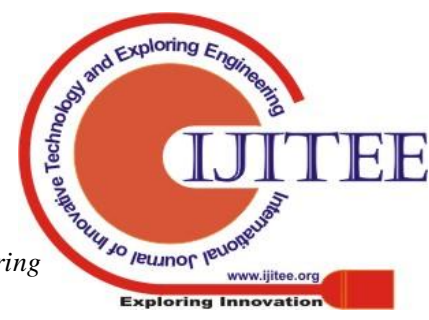


and intervention.

There are some other papers available in literature works on intelligent system using modules and sensors to connect with real time such as Intelligent Traffic system [5]. In this paper authors have proposed different ways to make traffic system smarter and reliable and in result it reduces the congestion in urban areas. They have proposed the model using RF modules, Bluetooth modules and some infrared proximity sensor to detect the density of vehicles in particular area.

The idea about reducing the traffic density in urban areas is good using this as it notifies the driver about the direction where the traffic is less. This technology or concept provides the best way to reduce the traffic in particular area and distributing the vehicles in every route. People can reach faster to their location and can reach on time. Most of the accidents due to the avoidance of the driver [6]. There are some other papers available in literature work [7] 'Control Issue in Automated Highway Systems' which is mainly focus on the control system. The outcome of the systems are some type of audible or visible therefore we use visible the speed of the vehicle and glow the LEDs [8].

\section{BLOCK DIAGRAM}

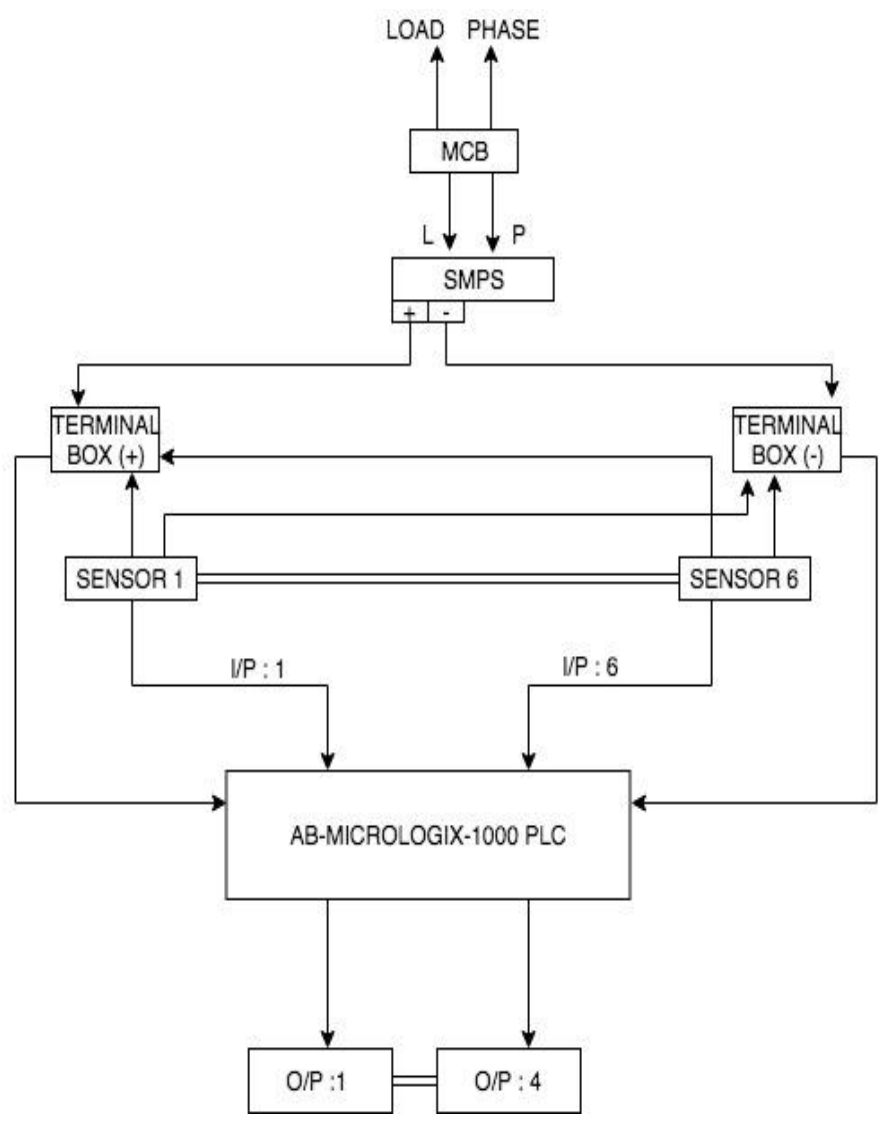

Fig.1 Block diagram of the proposed system

\section{A.Working}

The proposed model presented in Fig.1 is based on automation and its complete working is dependent on the programming of PLC. PLC will be programmed through RS logix 500.

Proposed system includes MCB for the protection of the system due over current the time of short circuit occurrence have also used SMPS for switching to convert input $\mathrm{AC}$ power of $(220 \mathrm{~V})$ into output DC power of (24VDC). This supply of $24 \mathrm{~V}$ dc is then supplied PLC has given 6 input Inductive proximity sensors. These sensors have the function of sensing the signal whenever object like any vehicle come close to it. Then it further passes the signal to the PLC and plc will give the output. Output change has been received via $24 \mathrm{~V}$ dc LEDs. It will glow when sensor sense any vehicle in the vicinity. The whole process work in milliseconds as PLC is fast and robust and can handle bigger program very easily. Thus PLC based system provides instant response by avoiding the situation of critical accidents.

\section{B. Components Required}

Table 1. Components required for the proposed system

\begin{tabular}{|l|l|}
\hline S.No. & COMPONENTS \\
\hline 1. & AB-MICROLOGIX 1000 - PLC \\
\hline 2. & PROXIMITY SENSORS \\
\hline 3. & SWITCH MODE POWER SUPPLY (SMPS) \\
\hline 4. & MINIATURE CIRCUIT BREAKER (MCB) \\
\hline 5. & TERMINAL BOXES \\
\hline 6. & CONNECTING WIRE \\
\hline 7. & LED \\
\hline
\end{tabular}

Table 1 shows the components required for designing proposed system. Each component has specific function involved in the whole process of automation. PLC, Proximity sensors, SMPS, MBCs and LEDs are the few main components involved in designing of the proposed system.

\section{Components Specifications}

Table 2. Components Specifications

Table 2 shows the particular specification of each component used in the proposed system. 


\begin{tabular}{|c|c|c|}
\hline S.No. & COMPONENTS & SPECIFICATIONS \\
\hline 1. & $\begin{array}{l}\text { AB-MICROLOGI } \\
\text { X } 1000 \text { - PLC }\end{array}$ & $\begin{array}{c}\text { i/p :- 26.4VDC } \\
\text { o/p :- 1A }\end{array}$ \\
\hline 2. & $\begin{array}{c}\text { PHOTOELECTRI } \\
\text { C SENSOR }\end{array}$ & 8-18 PNP NO SENSOR \\
\hline 3. & $\begin{array}{l}\text { SWITCH MODE } \\
\text { POWER SUPPLY } \\
\text { (SMPS) }\end{array}$ & $\begin{array}{c}\mathrm{i} / \mathrm{p}:-200-240 \mathrm{VAC}, 0.17 \mathrm{~A} \\
, 50 / 60 \mathrm{~Hz} . \\
\text { o/p :- +24VDC, 0.7A }\end{array}$ \\
\hline 4. & $\begin{array}{c}\text { TERMINAL } \\
\text { BOXES }\end{array}$ & For connections \\
\hline 5. & $\begin{array}{c}\text { CONNECTING } \\
\text { WIRE }\end{array}$ & 1 sq.mm, 1.5 sq.mm \\
\hline 6. & LED & $24 \mathrm{VDC}$ \\
\hline
\end{tabular}

\section{COMPONENTS DESCRIPTION}

\section{A. Miniature Circuit Board}

In the shown Fig. 2, A Miniature Circuit Breaker is used for the protection of the system by over current, in case of faulty conditions. It automatically operates and interrupts current during fault condition. It has current rating of $6 \mathrm{~A}$ of voltage of 220-250V.

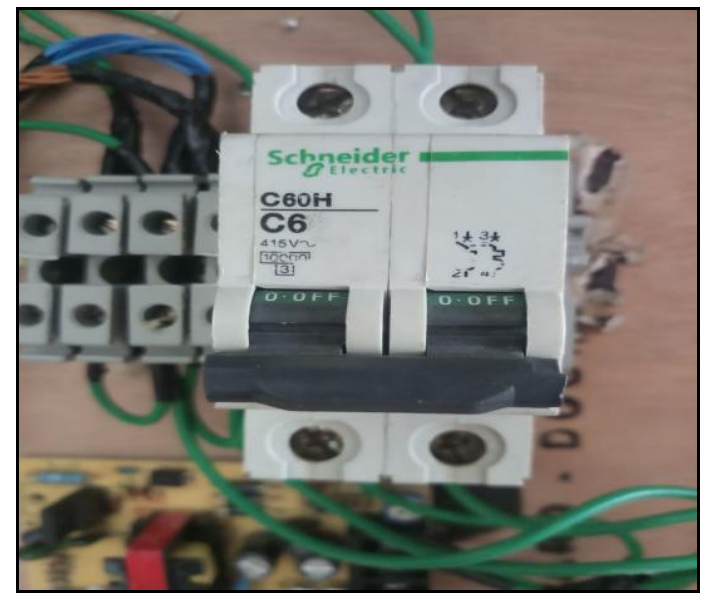

Fig. 2 Miniature Circuit Breaker (MCB)

\section{B.Switch Mode Power Supply}

A Switch Mode Power Supply is used for the change in input AC Power (220V) into DC Power (24V). It has been utilized for switching regulator to convert electrical power efficiently. Top view of the SMPS as shown in Fig. 3 below.

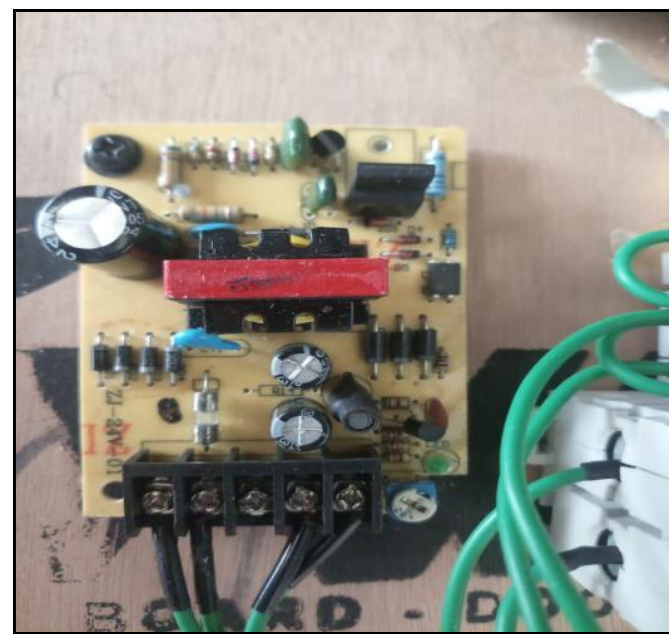

Fig. 3 Switch Mode Power Supply (SMPS)

\section{Programmable Logic Controller}

A PROGRAMMABLE LOGIC CONTROLLER (PLC) is a small computer (as shown in the Fig.4(a)) which is used in automation industries [2] which continuously scan/watches the state of input devices and gives output based upon a program that is saved in its non-volatile memory and control the state of output devices.

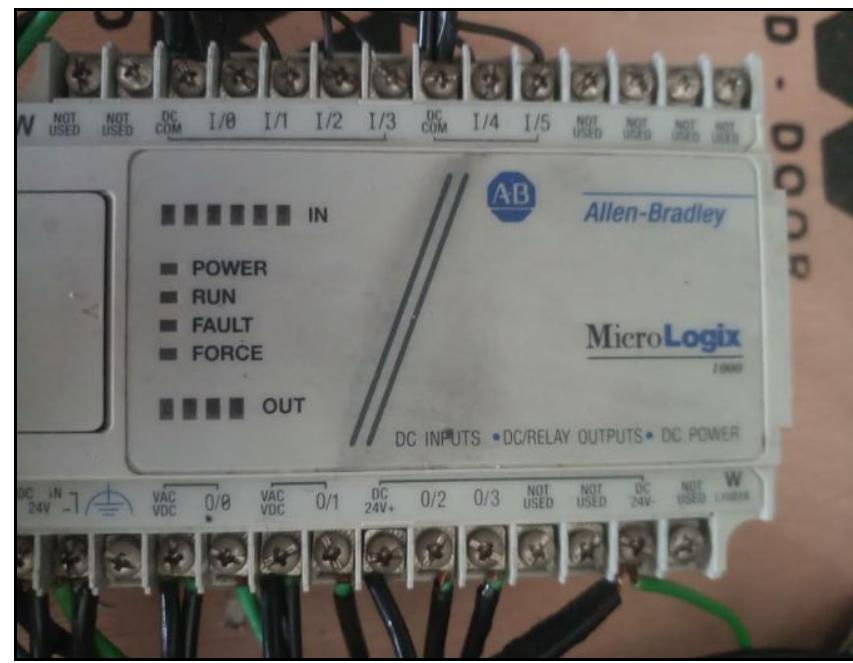

Fig. 4 (a) Programmable Logic Controller (PLC)

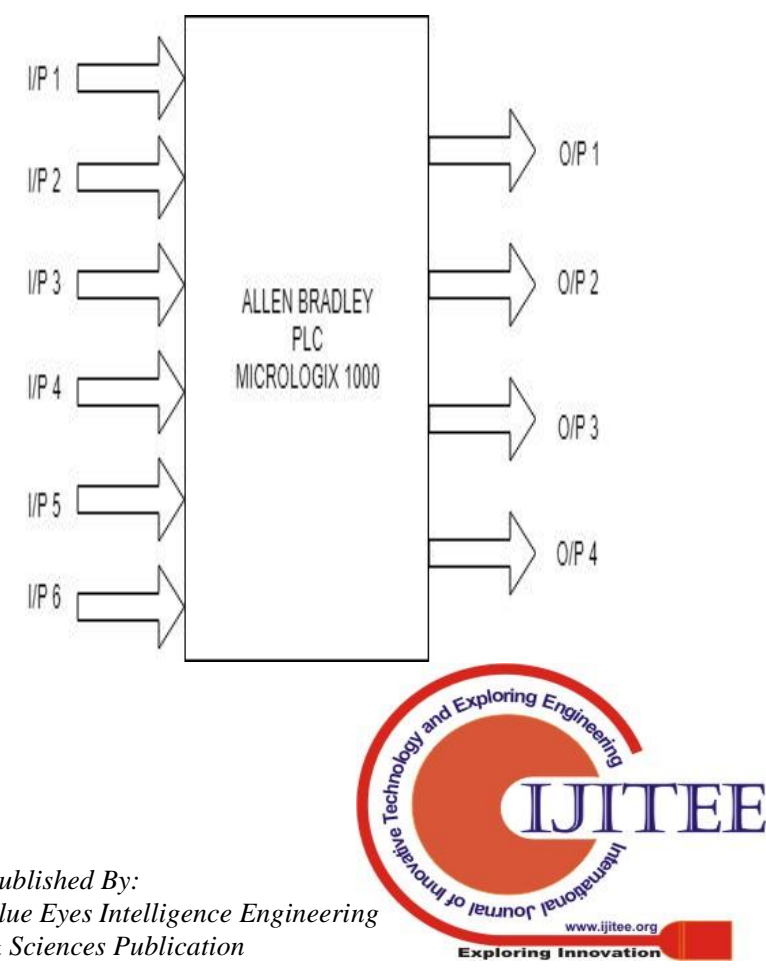


Notation in figure 4(b):

$\mathrm{I} / \mathrm{P}: 1$ - Inductive proximity sensor 1

$\mathrm{I} / \mathrm{P}: 2$ - Inductive proximity sensor 2

$\mathrm{I} / \mathrm{P}: 3$ - Inductive proximity sensor 3

$\mathrm{I} / \mathrm{P}: 4$ - Inductive proximity sensor 4

$\mathrm{I} / \mathrm{P}: 5$ - Inductive proximity sensor 5

I/P : 6 - Inductive proximity sensor 6

O/P : 1 - Red LED 1 (Alert Driver)

O/P : 2 - Red LED 2 (Alert Driver)

O/P : 3 - Red LED 3 (Alert Driver)

O/P : 4 - Red LED 4 (Alert Driver)

\section{Inductive Proximity Sensor}

It is the device which uses the principle of electromagnetic to measure or detect the objects. It is basically a metal detector. We use it for sensing the upcoming vehicles. It detects the vehicle and sends the signal to the PLC. Its sensing range varies from few 'mm to meters'. We mainly use the $8 \mathrm{~mm}$ inductive proximity sensor for our prototype only as shown in Fig.5. We can use photoelectric or distance sensor for real life implementations.

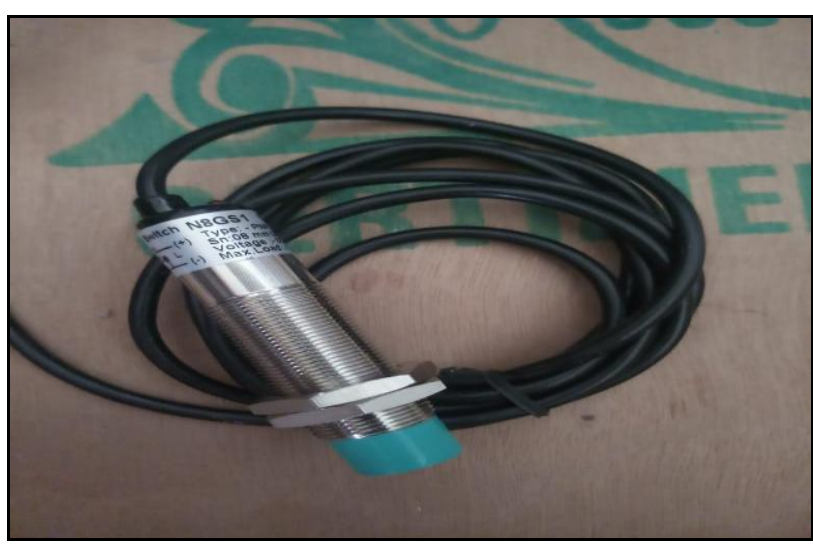

Fig. 5 Inductive Proximity Sensor

\section{E. Light Emitting Diode}

It is basically a semiconductor device which emits light when the current is passing through it. It is use for the alerting the driver by glowing light showing as indication or to the vehicle coming from the opposite end about the incoming of other vehicle from opposite end. It is shown in the Fig.6.

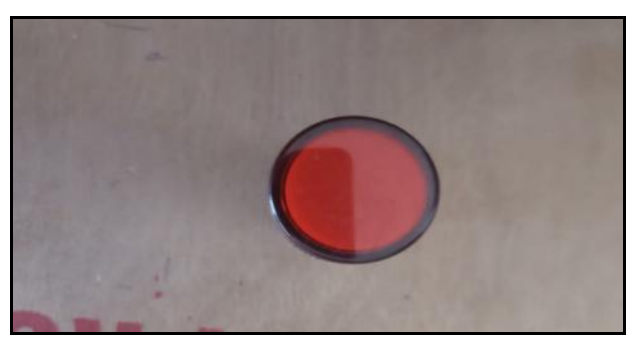

Fig.6. Light Emitting Diode (LED)

\section{OVERVIEW OF SYSTEM MODEL}

The proposed model based on PLC technology has the purpose of solving the accident problem on hilly areas. It has also been verified using system model has also been verified using system model.
The main objective of this work is to build a hardware that has:

a. The capability to collect the information about the incoming vehicle and sending signals to the PLC.

b. Alerting the driver of opposite end vehicle about incoming vehicle.

\section{A.Driver Alert System}

Driver Alert System is basically designed to avoid road accidents in hilly areas by alerting the drivers of opposite ends against arrival of each other. After alert signal like LED glows driver will slow down its speed thus avoiding quashing with each other. PLCs are utilized and programmed to get the desired output via sensors.

\section{B. Advantages}

1. Avoid possibilities of accident on hair pins.

2. Provide safe journey to the passengers.

3. Provide comfort to the driver on hair pins.

\section{C.Disadvantages}

1. This system will not work in winters due to snow weather.

2. In dense and foggy weather. It will be difficult for the sensor to detect vehicle.

\section{D.System Concept}

The proposed system is mainly divided into two parts :

1. Study and operation of PLC using software to program it.

2. Communicating the sensors with PLC and making it compatible for sensing the signals.

\section{PROPOSED SYSTEM}

This system will alert by glowing the LEDs and also showing the speed of incoming vehicle the opposite end driver of another incoming vehicle on hair bends or blind spot. After knowing that vehicle is coming from other side driver will slower down the vehicle to avoid any kind of mishappening.

The proposed technology involves the use PLC, inductive proximity sensor and other equipments to alert the driver. The basic prototype of system model is shown below in several steps.

\section{A.Step 1:}

Initially when a vehicle coming in a normal speed from one side of hair pin. It comes near to the proximity sensor, sensor will detect the object and will send the signal to the PLC. Here Sensor will work as a input to the PLC. When PLC will get the information from the sensor it will read the program inside its non-volatile

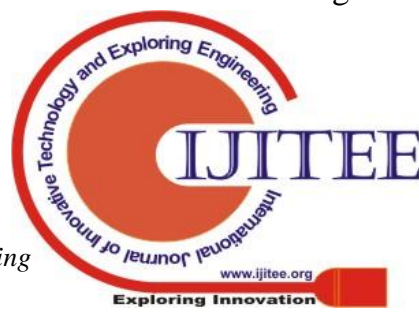


memory and see where to send the output. After completion of plc program it will automatically send the signal to the output as per the instructions.

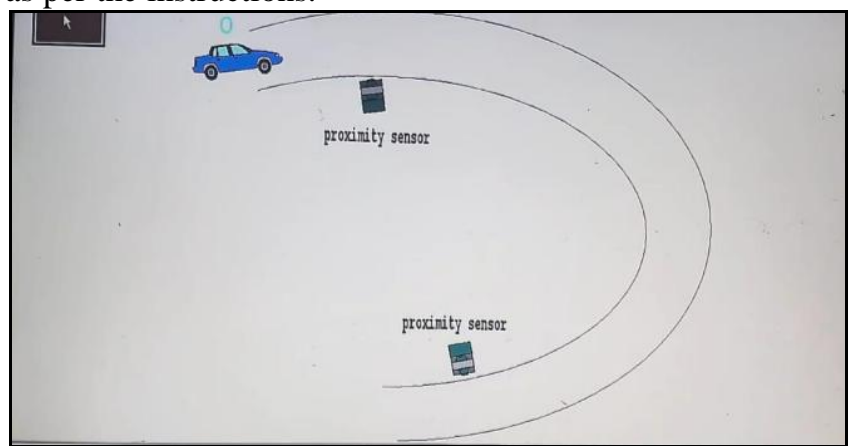

Fig. 6.1. Vehicle1 is coming from one side of the blind curve

\section{B.Step 2}

In this step the sensor senses the signal about the arrival of incoming car and sends the signal to the programmed PLC. PLC will turn ' $\mathrm{ON}$ ' the output, and alert the driver that is coming from the other direction by glowing the LEDs. It also shows the speed of the opposite end vehicles. The second car opposite end driver will decrease its speed as now driver is aware about the other side i.e. the vehicle is coming and will avoid any kind of accident.

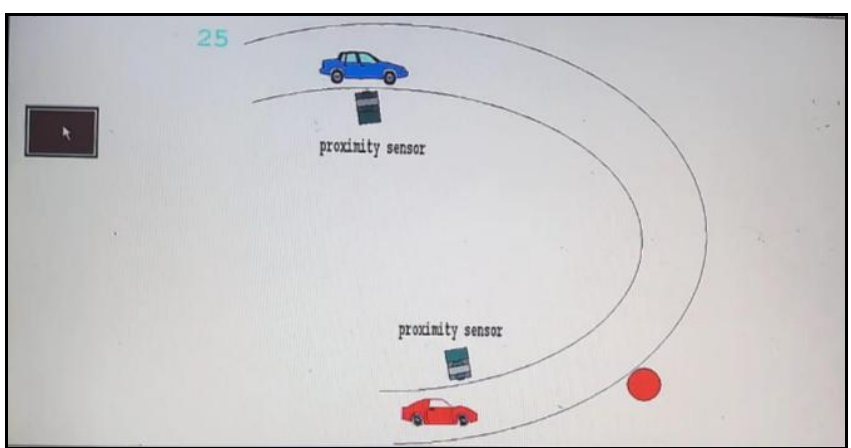

Fig.6.2. Vehicle1 crossing the inductive proximity sensors.

\section{C.Step 3}

Now the car that is coming from the opposite side will also get sensed by the sensor. Sensor will send the signal alert to the first car driver. Thus both the driver will slow down their vehicle.

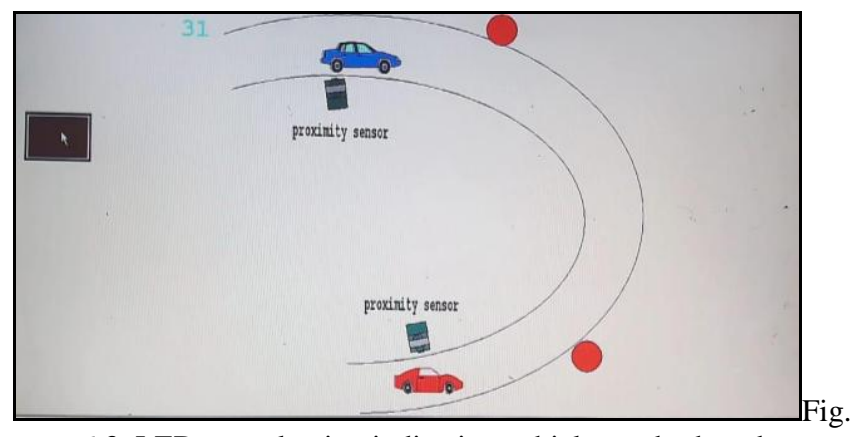

6.3. LEDs are glowing indicating vehicles on both ends.

\section{D.Step 4}

In this step as we can see both the driver are getting red signal, and should slow down their vehicle to avoid any kind of accident and should have peaceful journey on the hilly area.

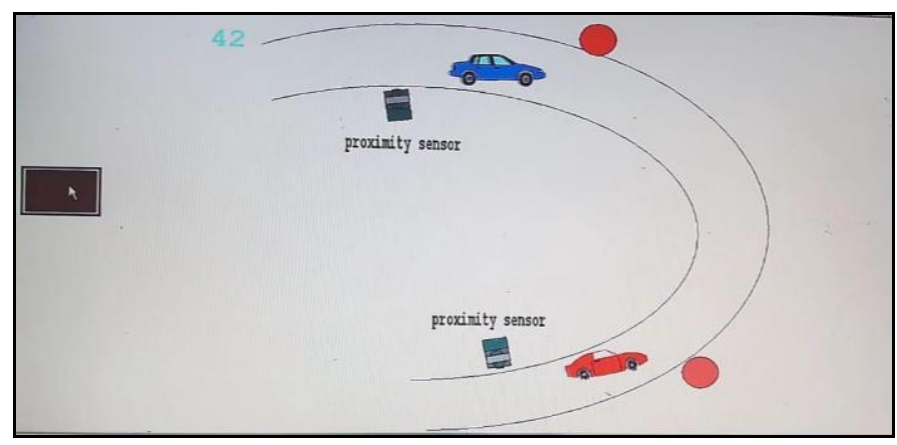

Fig. 6.4 Slow speed indication after alert signal using LED glow.

\section{FLOW CHART OF THE PROPOSED MODEL}

The working of the system is describing in the block format for easily understanding of the system working in the Flow Chart as shown below.

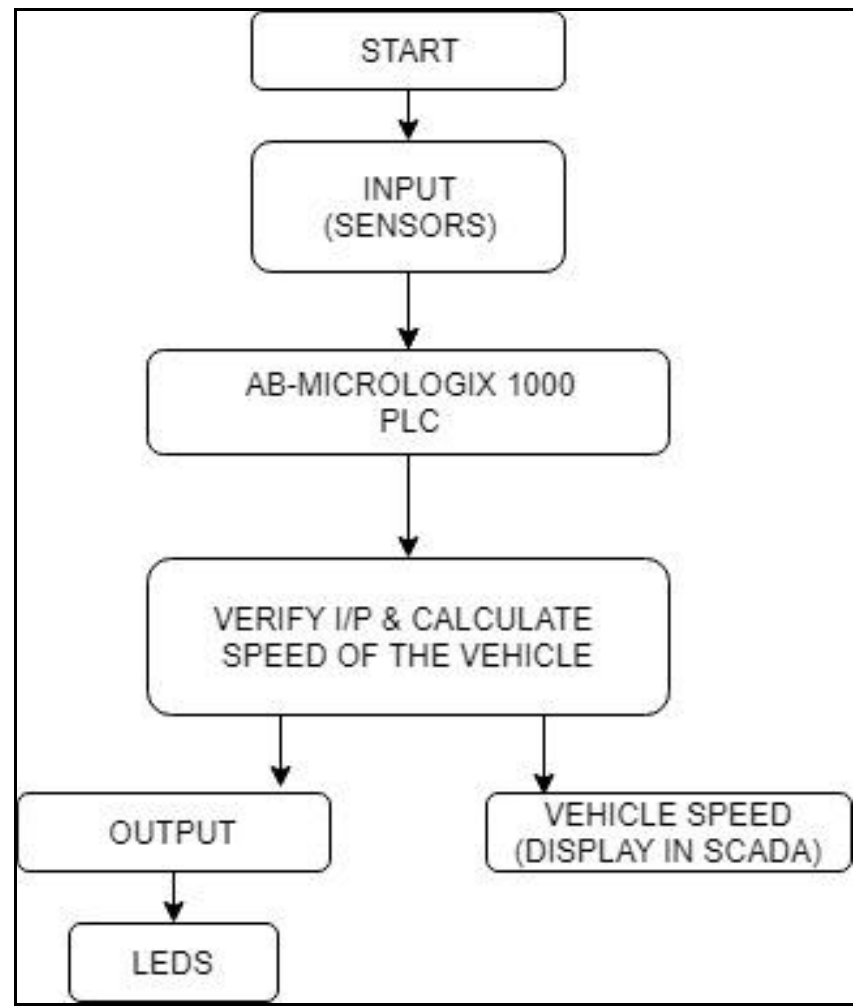

Fig. 7. Flow chart of the proposed model

\section{A. WORKING:}

The proposed method is based on Automation and complete working depends on programming of PLC which is done in the RS Logix 500.

\section{Step 1:}

The proposed system has 6 Inductive proximity sensors as input which senses the object when it comes close to it and sends the signal to the PLC

Step 2:

PLC receive the signals by the inductive proximity sensor and verify the signal/input if the signal is

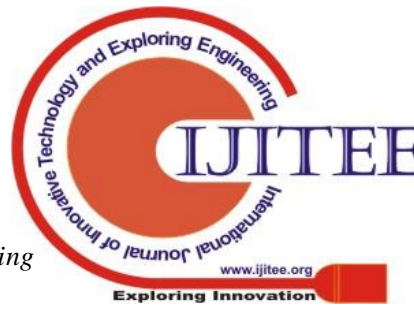


according to the programming then the PLC sends the Output.

Step 3:

PLC verify the signal according to it program and also calculate the speed of the vehicle because the formula of calculating the speed is already is in the PLC and sends the Output signals.

Step 4:

PLC sends the Output to the 24VDC LED to glow and also the speed of vehicle to the SCADA to show the speed of the vehicle.

\section{RESULT AND CONCLUSION}

Hilly areas have sharp turns and bends. Thus they are more prone to accidents endangering human life. To avoid such critical situation the Driver Alert System developed in this paper provide indication to the vehicles of the other side with the help of glowing LEDs showing the arrival of the vehicle from the opposite end.

Figure 8 shown below shows the working model of the proposed system under the condition when vehicles are coming from both the sides at hair pin. Thus it shows the red LEDs glowing at both the ends showing arrival of the vehicle from other end.

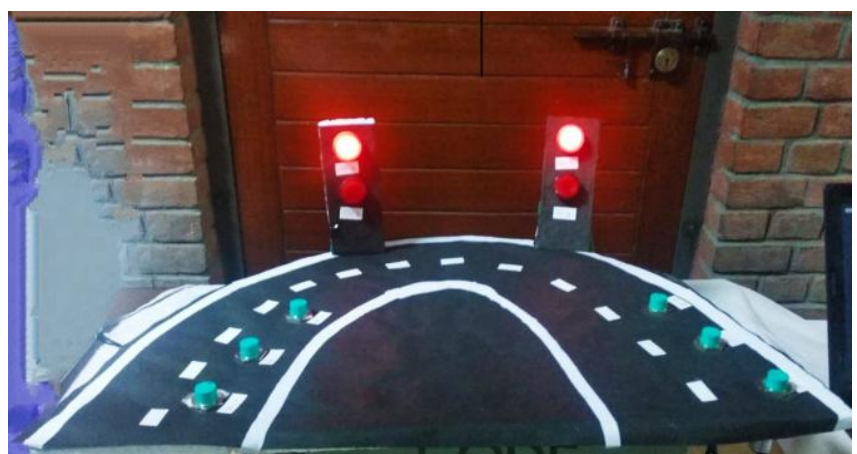

Fig. 8. Proposed model under working condition

Under this condition the driver of the other vehicle coming from the other side will slow down it speed. Speed range of the other vehicle will also shown via SCADA system. Thus Driver Alert System would also prevent high impact between the vehicles during accidents by showing the speed.

\section{REFERENCES}

[1] A. K. Gupta, G. Wable, T. Batra, "Collision Detection System for Vehicles in Hilly and Dense Fog Affected Area to Generate Collision Alerts" in International Conference on Issues and Challenges in Intelligent Computing Techniques (ICICT), 2014.

[2] S. Boopathi, K. Govindaraju, M. Sangeetha, M. Jagadeeshraja ,M. Dhanasu "Real time based smart vehicle monitoring and alert using GSM" in International Journal of Advanced Research in Computer and Communication Engineering, vol. 3, Issue 11, November 2014.

[3] https://www.hindustantimes.com/business-news/hp-leo-burnett-make -smart-poles-for-roads-that-honk-to-alert-drivers-on-blind-turns/story -gxkiMJjHWfCyMWhFTpyrGJ.html

[4] K. Aravind, D. Hardley, Pradeep, T. Vijayan, B. K. Selvi, S. Latha, "Automation of space management in vehicle parking using PLC and SCADA" International Journal of MC Square Scientific Research vol.9, no.2, 2017.
[5] S. P. Biswas, P. Roy, N. Patra, A. Mukherjee and N. Dey, " Intelligent Traffic Monitoring System", Second International Conference on Computer and communication Technologies, Advances in Intelligent Systems and Computing

[6] M. H. Alsibai, S. A. Manap,"A study on Driver fatigue notification systems", ARPN Journal of Engineering and Applied Sciences, vol. 11 no. 18 , September 2016

[7] J. K. Hedrick, M. Tomizuka, and P. Varaiya,"Control Issue in Automated Highway Systems" IEEE Control Systems, December 1994.

[8] Kanchan Manohar Sontakke "Efficient Driver Fatigue Detection and Alerting System", International Journal of Scientific and Research Publications, vol.5, no. 7, July 2015.

\section{AUTHORS PROFILE}

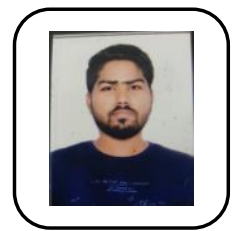

Bishwajeet Singh has done B.Tech from Amity University Uttar Pradesh, batch 2015-19 in Electrical and Electronics Engineering. He has done internship in Indian Railway on the topic of Maintenance Electric Loco.

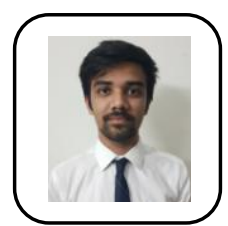

Mohit Arvind has done B.Tech from Amity University Uttar Pradesh, batch 2015-19 in Electrical and Electronics Engineering. He has done internship at NTPC ANTA - Gas Power Plant.

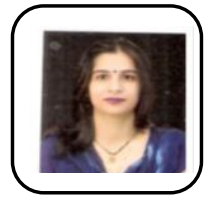

Divya Asija is currently pursuing Ph.D in Electrical Engineering from Amity University, Uttar Pradesh. She received her $M$. Tech from YMCA institute of Engineering Faridabad and B. E. from Apeejay College of Engineering, Sohna, Gurgaon. She has teaching experience of 11 years. During her academic career she held various key administrative positions. She has published several research papers in reputed international journals and conferences. Her professional interests include Congestion Management in Transmission System, Distributed Generation and other related field in power system.

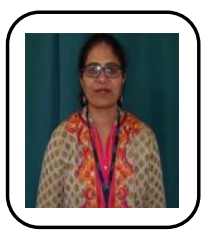

Pallavi Choudekar is currently pursuing $\mathrm{Ph} . \mathrm{D}$ in Electrical Engineering from Amity University, Uttar Pradesh. She received her $M$. Tech from Gautam Buddha Technical University, Uttar Pradesh and B. E. from Pune University. She has teaching experience of 16 years. During her academic career she held various key administrative positions. She has published several research papers in reputed international journals and conferences.

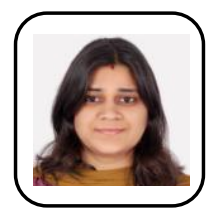

Ruchira received the M.E degree in Electrical Engineering from the PEC University of Technology, Chandigarh in 2009. She has around 9 years of teaching. Presently, she is working as an Assistant Professor in the department of Electrical and Electronics Engineering at Amity University, Uttar Pradesh. Her research interests include power system control and renewable energies. 